Article

\title{
Optimization of Fermentation Condition for Echinacoside Yield Improvement with Penicillium sp. H1, an Endophytic Fungus Isolated from Ligustrum lucidum Ait Using Response Surface Methodology
}

\author{
Fangxue Xu, Hui Cao, Xiaowei Cui, Hong Guo and Chunchao Han * (D) \\ School of Pharmacy, Shandong University of Traditional Chinese Medicine, Jinan 250355, China; \\ xfx18364164925@163.com (F.X.); 13553158985@163.com (H.C.); 13553159162@163.com (X.C.); \\ 13589080261@163.com (H.G.) \\ * Correspondence: chunchaoh@126.com; Tel./Fax: +86-531-82613129
}

Received: 20 September 2018; Accepted: 1 October 2018; Published: 10 October 2018

\begin{abstract}
Background: Application of echinacoside has become increasingly important for its significant biological activities. However, there are many disadvantages in existing synthesis methods such as contaminating the environment, harsh reaction conditions and so on. Therefore, it is urgent to invent a novel alternative method that can increase the yield of echinacoside. (2) Methods: In this study, we isolated and purified an endophyte from the leaves of Ligustrum lucidum Ait. Then, we improved the yield of echinacoside by optimizing the fermentation condition with an endophytic fungus. Penicillium sp. $\mathrm{H} 1$ was isolated from Ligustrum lucidum Ait. In addition, response surface methodology was used to optimize the fermentation condition. (3) Results: The results indicate that the maximal yield of echinacoside $(37.16 \mathrm{mg} / \mathrm{L})$ was obtained when inoculation rate, temperature and days were $13.98 \%, 27.85{ }^{\circ} \mathrm{C}$ and 26.06 days, respectively. The yield of echinacoside was 150.47 times higher under the optimal conditions than under the control conditions. The results indicate that the yield of echinacoside could be improved with endophytic fermentation by optimizing the fermentation condition. We provide an alternative method for echinacoside production by endophytic fermentation in this paper. It may have a profound effect on the application of echinacoside.
\end{abstract}

Keywords: Echinacoside; Endophytes; Ligustrum lucidum Ait; Response surface methodology

\section{Introduction}

Endophytes are non-pathogenic bacteria and fungi that grow intra- or extracellularly in healthy plant tissues such as bark, flowers, roots, stems, leaves and seeds [1-3]. There are two transmission routes by which endophytes can be obtained: horizontally from the environment via soil, atmosphere and insects; or vertically from generation to generation via seeds and pollen [4]. Wani et al. [5] summarized that endophytic biology has been studied in numerous targets which can be divided into two categories: bio-prospecting and plant-microbe symbiosis (Figure 1). Endophytes can be used in several industrial branches such as medicine, biotechnology, agriculture, and industrial manufacturing of antimicrobials, insecticides and anti-cancer agents [6-8]. It is well known that endophytes can improve plant productivity, stress tolerance and promote phytoremediation [9]. $\mathrm{Xu}$ et al. [10] summarized that endophytes could promote the production of rare pharmaceutical metabolites by bio-process optimization strategies. Hence, we studied the technology for isolating and 
purifying endophytes from plant tissues. In addition, we utilized endophytic fermentation to promote the important component in the plant.

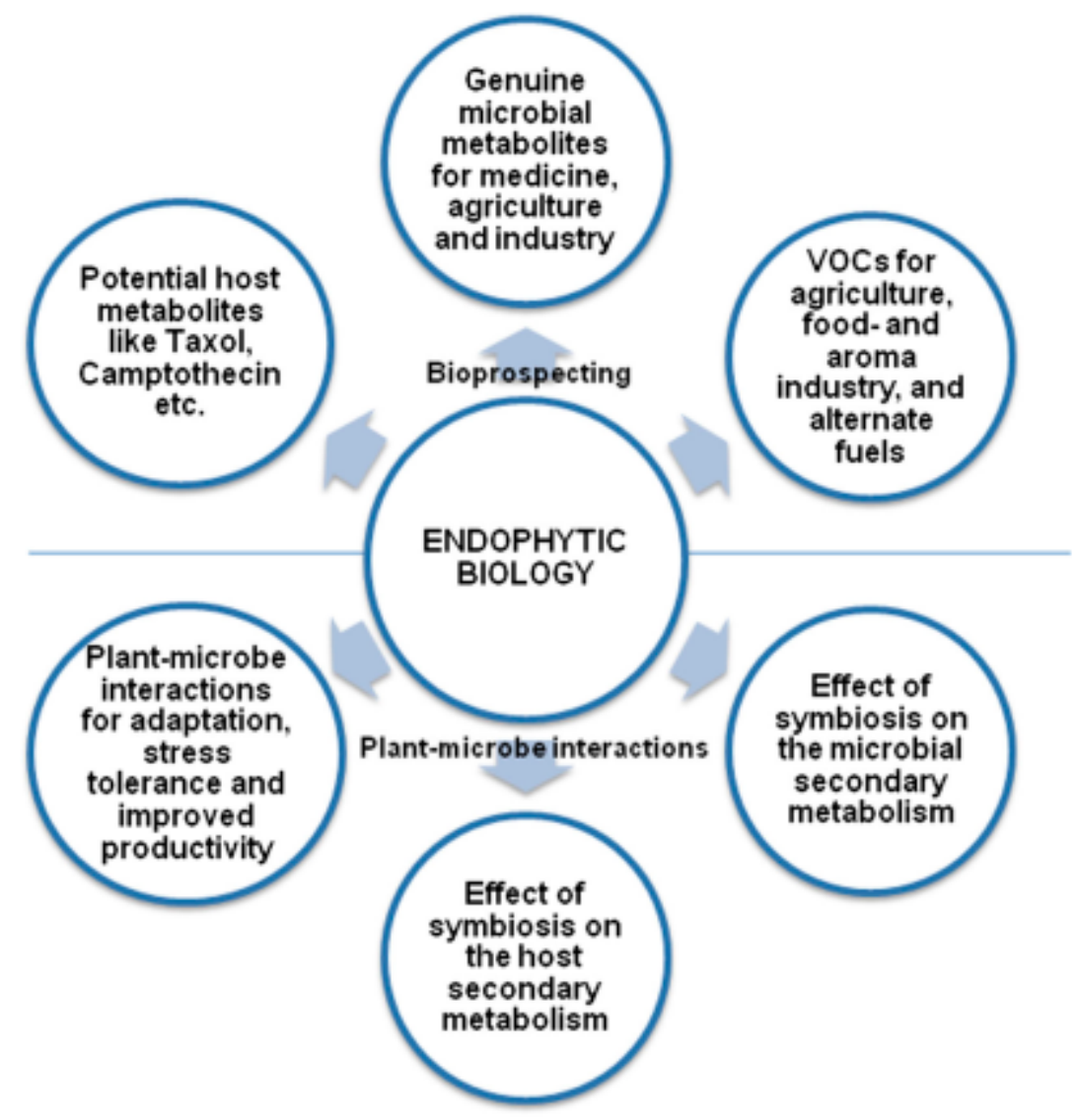

Figure 1. The biological study of endophytes.

Echinacoside $(\mathrm{ECH})$ is a natural phenylethanoid glycoside extracted from the medicinal Chinese herb Ligustrum lucidum Ait. Figure 2 shows the chemical structure of ECH. It resides also in several other plants such as Cistanche tubulosa (Schrenk) Wight and Echinacea angustifolia [11]. ECH has many valid pharmacological effects such as anti-hyperglycemic [12], anti-inflammatory [13,14], antiosteoporotic [15-17], photoprotective [18,19], liver protection [20-22], anti-Alzheimer's disease [23-27], protection of testis and sperm injury [28,29], anticancer [30-32] and so on. Although ECH has a wide range of medical uses and familiarities, the amount extracted from plants is low. In general, the concentration of the extracted ECH can be improved by complicated chemical purification process. However, the chemical purification process has disadvantages such as high cost, environmental pollution and so on. Thus, there is an urgent need to find a novel method for obtaining high purity ECH. In this paper, we used endophytic fermentation to increase the content of ECH. It is a novel alternative method to increase the yield of ECH.

Response surface methodology (RSM) is a collection of statistical and mathematical techniques. RSM is used to obtain the optimal parameters in complex systems by constructing mathematical models and analysis of regression and variance $[33,34]$. It has been used for optimizing the submerged fermentation medium and culture conditions $[35,36]$. The statistical model based on the Box-Behnken design (BBD) is one of the response surface design methods [37]. In this study, we isolated and identified endophytes from L. lucidum Ait. Furthermore, RSM was applied to optimize the fermentation condition for improving the yield of ECH. 


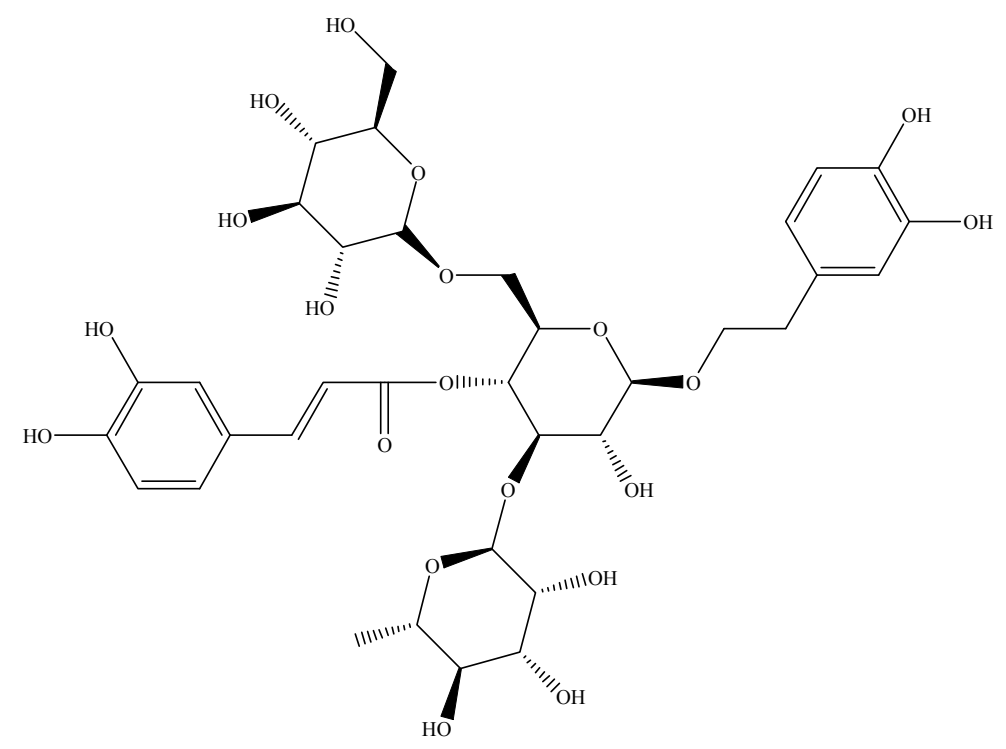

Figure 2. Chemical structure of ECH.

\section{Results and Discussion}

\subsection{Identification of Endophyte A. terreus}

The purified strain was identified as Penicillium sp. H1. The center of the strain colony was green. The edge of the strain was white. The colonial morphology was round. The ITS sequence was BLAST matched with GenBank database on homology, and the similarity with ribosomal rDNA of Penicillium sp. was 100\%. The purified strain is shown in Figure 3.

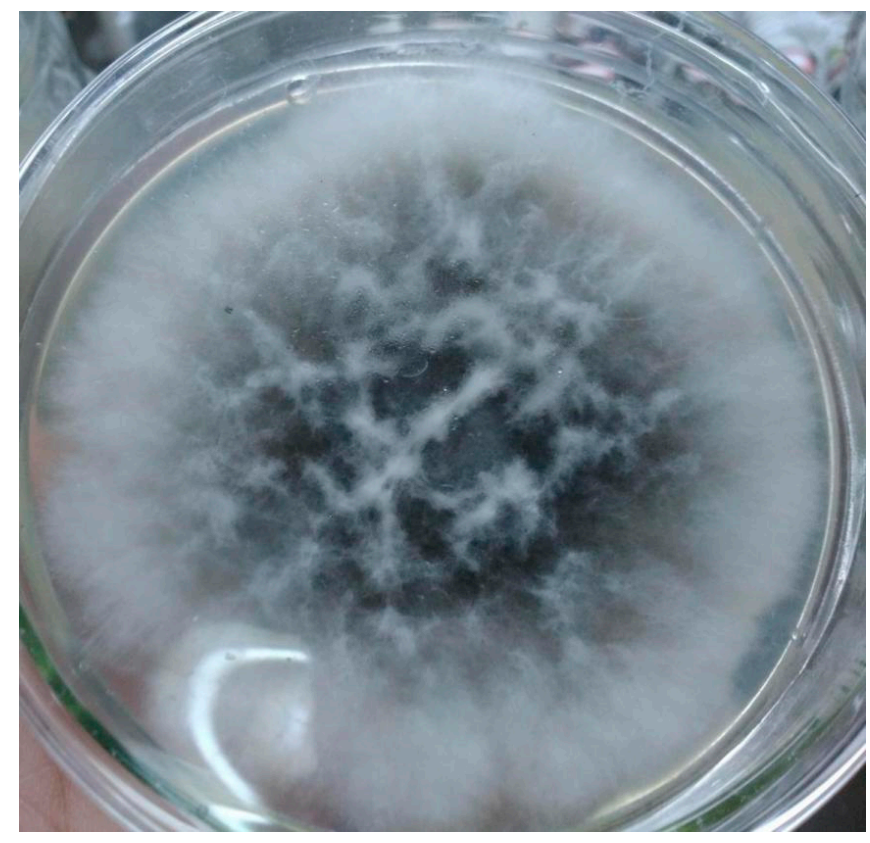

Figure 3. The purified strain in PDA medium.

\subsection{HPLC Chromatogram of ECH}

$\mathrm{ECH}$ was eluted at a retention time of $32 \mathrm{~min}$, the same retention time as the reference standard. Figure $4 \mathrm{a}$ shows the retention time of the reference standard. Figure $4 \mathrm{~b}$ shows the maximum $\mathrm{ECH}$ yield under the optimal conditions. 


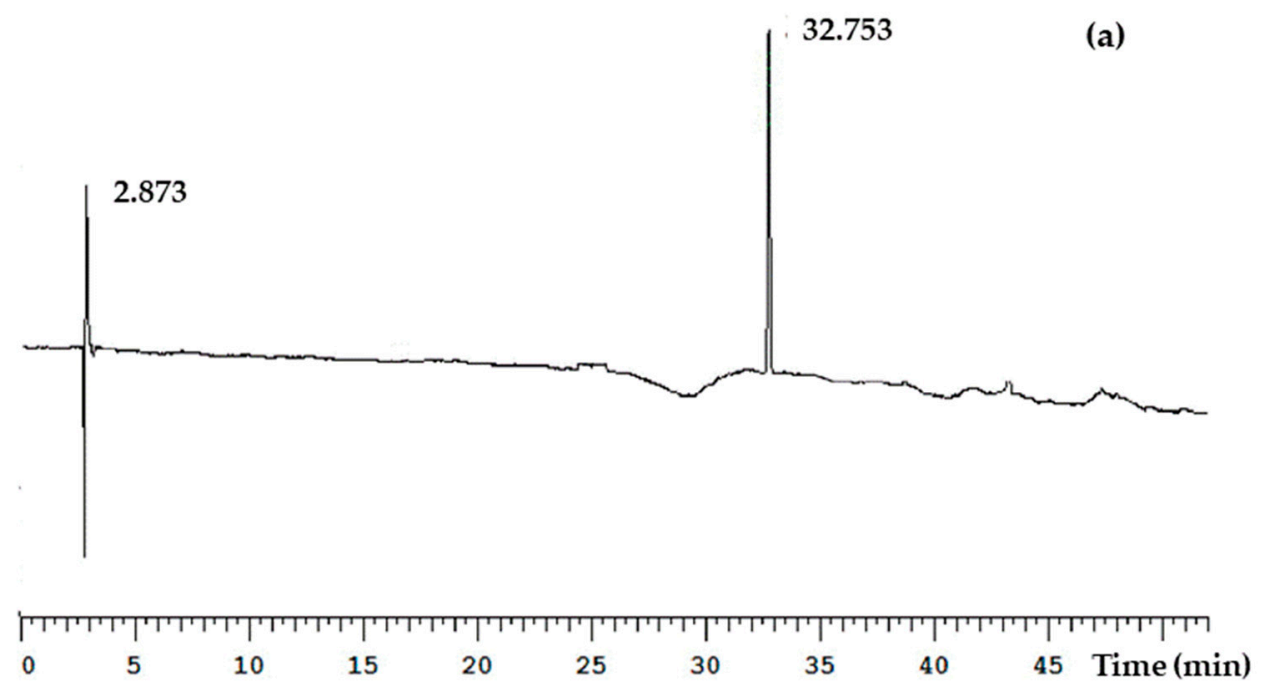

(b)

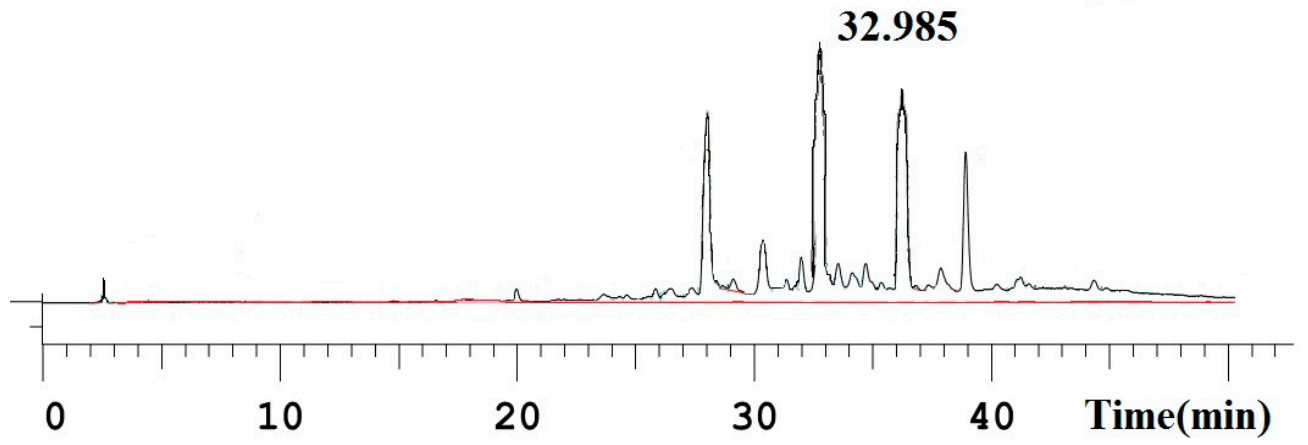

Figure 4. High performance liquid chromatography of: ECH standard (a); and sample (b). Sample: Fermentation products. The analytical conditions: chromatographic column: ZORBAX Eclipse XDB C18 column $(250 \times 4.6 \mathrm{~mm}, 5 \mu \mathrm{m})$; mobile phase: acetonitrile (A) $-0.1 \%$ formic acid solution (B); elution condition: $0-10 \mathrm{~min}, 7-12 \%$ A; 10-35 $\mathrm{min}, 12-75 \% \mathrm{~A} ; 35-50 \mathrm{~min}, 100 \% \mathrm{~A}$; column temperature: $25^{\circ} \mathrm{C}$; detect wave length: $280 \mathrm{~nm}$; and flow: $1 \mathrm{~mL} / \mathrm{min}$.

\subsection{Optimizing the Fermentation Conditions by RSM}

The BBD was utilized to assess the influence of three individual factors including inoculation rate $\left(X_{1}\right)$, temperature $\left(X_{2}\right)$, days $\left(X_{3}\right)$ and their interaction effects on the yield of $\mathrm{ECH}$. The experimental and predicted values of ECH under different treatment conditions are shown in Table 1. The predicted response $\mathrm{Y}$ for $\mathrm{ECH}$ production in terms of coded factors is expressed as follow:

$$
\begin{gathered}
Y=36.98-1.76 X_{1}-0.46 X_{2}+1.54 X_{3}-0.42 X_{1} X_{2}-1.99 X_{1} X_{3}+0.50 X_{2} X_{3}-9.62 X_{1}{ }^{2}- \\
10.13 X_{2}^{2}-8.17 X_{3}^{2}
\end{gathered}
$$

where $\mathrm{Y}$ is the response variable of $\mathrm{ECH}$, and $\mathrm{X}_{1}, \mathrm{X}_{2}$ and $\mathrm{X}_{3}$ are independent variable in coded units. The regression model was statistically detected in the shape of an F-test, and ANOVA, which was utilized to evaluate the significance and adequacy of the model (Table 2) [38]. 
Table 1. Design and experimental results of Box-Behnken design.

\begin{tabular}{ccccccc}
\hline \multirow{2}{*}{ Standard } & Run Order & $\mathbf{X}_{\mathbf{1}}$ & $\mathbf{X}_{\mathbf{2}}$ & $\mathbf{X}_{\mathbf{3}}$ & The Yield of ECH \\
\cline { 6 - 7 } & & & & & Experimental & Predicted \\
\hline 3 & 1 & -1 & 1 & 0 & 19.31 & 18.95 \\
13 & 2 & 0 & 0 & 0 & 36.98 & 36.98 \\
8 & 3 & 1 & 0 & 1 & 17.21 & 16.99 \\
7 & 4 & -1 & 0 & 1 & 26.05 & 24.48 \\
15 & 5 & 0 & 0 & 0 & 37.02 & 36.98 \\
12 & 6 & 0 & 1 & 1 & 18.34 & 20.26 \\
17 & 7 & 0 & 0 & 0 & 36.93 & 36.98 \\
1 & 8 & -1 & -1 & 0 & 17.34 & 19.05 \\
9 & 9 & 0 & -1 & -1 & 20.03 & 18.11 \\
10 & 10 & 0 & 1 & -1 & 16.04 & 16.18 \\
4 & 11 & 1 & 1 & 0 & 16.31 & 14.60 \\
5 & 12 & -1 & 0 & -1 & 17.21 & 17.43 \\
6 & 13 & 1 & 0 & -1 & 16.31 & 17.88 \\
16 & 14 & 0 & 0 & 0 & 36.91 & 36.98 \\
11 & 15 & 0 & -1 & 1 & 20.33 & 20.19 \\
2 & 16 & 1 & -1 & 0 & 16.01 & 16.36 \\
14 & 17 & 0 & 0 & 0 & 37.08 & 36.98 \\
\hline
\end{tabular}

Table 2. ANOVA results of the quadratic model.

\begin{tabular}{cccccc}
\hline Source & Sum of Squares & df & Mean Square & $\boldsymbol{F}$-Value & $\begin{array}{c}\boldsymbol{p} \text {-Value } \\
\text { Probability }>\boldsymbol{F}\end{array}$ \\
\hline Model & 1293.49 & 9 & 143.72 & 54.21 & $<0.0001$ \\
$\mathrm{X}_{1}$ & 24.75 & 1 & 24.75 & 9.33 & 0.0184 \\
$\mathrm{X}_{2}$ & 1.72 & 1 & 1.72 & 0.65 & 0.4470 \\
$\mathrm{X}_{3}$ & 19.03 & 1 & 19.03 & 7.18 & 0.0316 \\
$\mathrm{X}_{1} \mathrm{X}_{2}$ & 0.70 & 1 & 0.70 & 0.26 & 0.6239 \\
$\mathrm{X}_{1} \mathrm{X}_{3}$ & 15.76 & 1 & 15.76 & 5.95 & 0.0449 \\
$\mathrm{X}_{2} \mathrm{X}_{3}$ & 1.00 & 1 & 1.00 & 0.38 & 0.5585 \\
$\mathrm{X}_{1}{ }^{2}$ & 389.32 & 1 & 389.32 & 146.85 & $<0.0001$ \\
$\mathrm{X}_{2}{ }^{2}$ & 431.71 & 1 & 431.71 & 162.84 & $<0.0001$ \\
$\mathrm{X}_{3}{ }^{2}$ & 281.27 & 1 & 281.27 & 106.10 & $<0.0001$ \\
Residual & 18.56 & 7 & 2.65 & & $<0.0001$ \\
Lack of fit & 18.54 & 3 & 6.18 & 1306.47 & \\
Pure error & 0.019 & 4 & $4.730 \times 10^{-3}$ & & \\
Cor total & 1312.05 & 16 & &
\end{tabular}

The $p$-value was less than 0.05 , demonstrating that model term was significant. As shown in Table 2, the coefficient for $\mathrm{X}_{1}$ and $\mathrm{X}_{3}$ was significant $(p<0.05)$, indicating that the variables including inoculation rate and days had a significant influence on the yield of ECH. The $F$-value (54.21) suggested that the model was significant. The model was significant with a very low $p$-value $<0.01$ ( $p$-value Probability $>F)$. The values of $R^{2}(0.9859)$ and adjusted $R^{2}(0.9677)$ were closed to 1 , indicating the high efficacy of Equation (1). The value of adequate precision was 17.92, indicating that the model had an adequate signal and could be utilized to navigate the design space. In conclusion, the regression model for ECH yield was a good prediction of the experimental results and the factor effects were real.

Figure 5 displays the response surface curves as interaction of inoculation rate, temperature and days on ECH yield. It directly shows the response over a region of independent variables and the relationship between experimental levels of each factor. Figure 5a represents the effects of inoculation rate and temperature on $\mathrm{ECH}$ yield, showing that $\mathrm{ECH}$ yield increased upon increasing inoculation rate and temperature. A maximal ECH production was obtained when the inoculation rate was $13.98 \%$ 
and temperature was $27.85^{\circ} \mathrm{C}$. Subsequently, the ECH production declined with inoculation rate and temperature increase. Figure $5 b$ shows that increasing days to more than 26.06 days let to decrease of ECH yield. Simultaneously, Figure 5c displays the effects of temperature and days on ECH yield. The trend in Figure $5 \mathrm{c}$ is similar to that in Figure 5a,b. Finally, the optimal conditions of inoculation rate, temperature and days were found to be $13.98 \%, 27.85^{\circ} \mathrm{C}$ and 26.06 days, respectively. In addition, the predicted yield of ECH was $37.16 \mathrm{mg} / \mathrm{L}$ under the optimal conditions. To ensure the stability of the model equation for predicting the optimal conditions, the experiment was repeated using the optimal conditions. The average result was $37.09 \pm 0.11 \mathrm{mg} / \mathrm{L}$. In comparison, the yield of ECH was 150.47 times higher than the control (ethanol extract and water (1:20)).
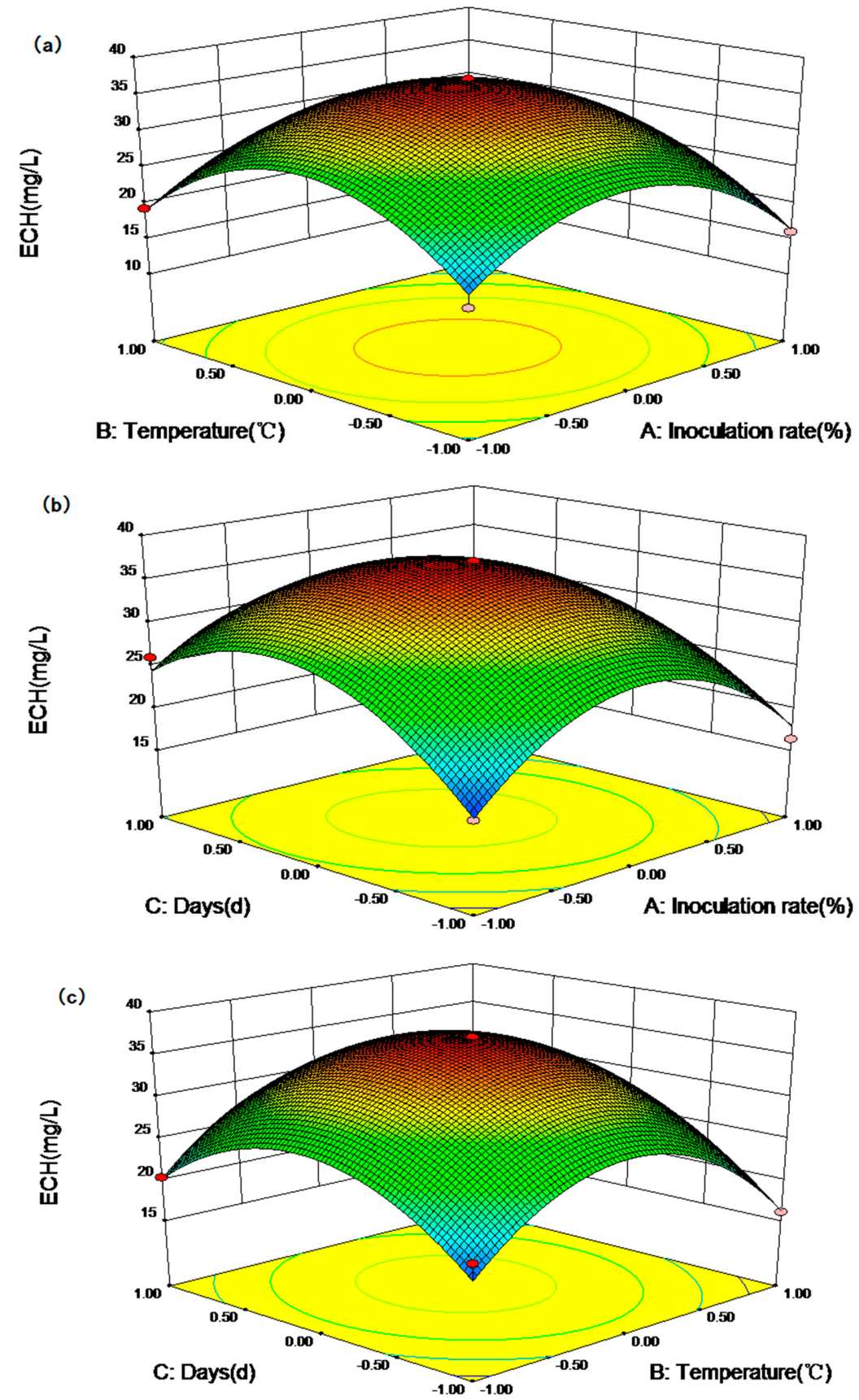

Figure 5. Response surface curves of $\mathrm{ECH}$ production: the interaction between inoculation rate and temperature (a); the interaction between inoculation rate and days (b); and the interaction between temperature and days (c). 


\section{Materials and Methods}

\subsection{Reagents and Instruments}

The reference standard of ECH was purchased from Shanghai YuanYe Biotechnology Co., Ltd. (Shanghai, China); glucose and peptone were purchased from Beijing AoBoXing Bio-Tech Co. Ltd. (analytical grade, Beijing, China); $\mathrm{KH}_{2} \mathrm{PO}_{4}$ and $\mathrm{MgSO}_{4} \cdot 7 \mathrm{H}_{2} \mathrm{O}$ were purchased from Sinopharm Chemical Reagent Co. Ltd. (analytical grade, Shanghai, China); methanol, ethanol, acetonitrile, and formic acid were purchased from Sinopharm Chemical Reagent Co. Ltd. (chromatographic grade, Shanghai, China); and $\mathrm{HgCl}_{2}$ was purchased from Tianjin dongfang chemical factory (analytical grade, Tianjin, China).

TDL-5-A centrifuge (ShangHai Anting Scientific Instrument Factory, Shanghai, China); L-2000 Elite high performance liquid chromatograph (Hitachi Limited, Tokyo, Japan); KQ 5200E ultrasound cleaner (Kunshan ultrasonic instrument Co. Ltd., Kunshan, China); LRH-250-Z incubator (medical equipment factory in Guangdong, China); and HX-I incubator shaker (medical equipment factory in Guangdong, China) comprise the used equipment.

\subsection{Isolation of Endophytes}

The leaves of L. lucidum Ait were collected from Shandong University of Traditional Chinese Medicine, China in June 2017. Isolation of the endophytes was carried out according to previous methods with minor changes [39]. Leaves were cut into $1 \times 1 \mathrm{~cm}^{2}$ squares under aseptic conditions. Leaves of L. lucidum Ait were immersed in 75\% ethanol for 2 min and washed twice with sterile water. Then, the leaves were immersed in $0.1 \% \mathrm{HgCl}_{2}$ for $3 \mathrm{~min}$ and washed three times with sterile water. Finally, the leaves were cultivated in potato dextrose agar medium (PDA: potato $200 \mathrm{~g} / \mathrm{L}$, dextrose $20 \mathrm{~g} / \mathrm{L}$, agar $20 \mathrm{~g} / \mathrm{L}$ ) at $27^{\circ} \mathrm{C}$ for 5 days. The last flush of sterile water as a control was cultured in PDA medium at $37^{\circ} \mathrm{C}$ for 5 days. If no microbial growth was found in control, the process of sterilization was successful. The mycelium was transferred into another PDA medium about four times by picking the pure strains for purification. The identification of endophyte was consigned to Shanghai Majorbio Bio-pharm Technology Co., Ltd., Shanghai, China for 16S rDNA sequence analysis and physiological and biochemical characteristics detection.

\subsection{Preparation of Seed Broth}

The acquisition of inoculum was achieved by transferring a few of purified endophyte into seed medium (potato $200 \mathrm{~g} / \mathrm{L}$, glucose $20 \mathrm{~g} / \mathrm{L}, \mathrm{KH}_{2} \mathrm{PO}_{4} 0.5 \mathrm{~g} / \mathrm{L}, \mathrm{MgSO}_{4} \cdot 7 \mathrm{H}_{2} \mathrm{O} 0.5 \mathrm{~g} / \mathrm{L}$ ) on the rotary shaker at $180 \mathrm{rpm}$ for 7 days.

\subsection{Ethanol Extract of L. lucidum Ait}

First, 70\% ethanol $9.5 \mathrm{~mL} / \mathrm{g}$ and $100 \mathrm{~g}$ L. lucidum Ait were added to the round bottom flask for water bath reflux extraction over $100 \mathrm{~min}$. The supernatant was obtained by centrifuging for $10 \mathrm{~min}$ at $4000 \mathrm{rpm}$. The supernatant was evaporated to dryness and weighed.

\subsection{RSM for Optimizing the Fermentation Conditions of ECH}

The dry substance of ethanol extract and water (1:20) were used for the culture medium of endophyte. The fermentation culture was carried out on a rotary shaker incubator at $160 \mathrm{rpm}$. The RSM was used to determine the yield of ECH affected by three factors (inoculation rate, temperature, and days). The yield of ECH was defined as response value. The Box-Behnken factorial design is shown in Table 3. The software Design-Expert 8.0.5.0 trial was utilized in experimental design, data analysis, and quadratic equation construction [40]. Independent variables were coded according to the following formula.

$$
X_{i}=\left(X_{i}-X_{0} / \Delta X_{i}(i=1,2,3)\right.
$$


where $X_{i}$ is the coded values of $X_{i}, X_{i}$ is the real value of an independent variable, $X_{0}$ is the real value of independent variables on the center point and $\Delta X_{i}$ is the step change value [40].

Table 3. Variables and experiments design level for RSM.

\begin{tabular}{ccccc}
\hline \multirow{2}{*}{ Variables } & \multirow{2}{*}{ Coded Symbols } & \multicolumn{3}{c}{ Coded Levels } \\
\cline { 3 - 5 } & & $\mathbf{- 1}$ & $\mathbf{0}$ & $\mathbf{1}$ \\
\hline Inoculation rate $(\%)$ & $\mathrm{X}_{1}$ & 5 & 15 & 25 \\
Temperature $\left({ }^{\circ} \mathrm{C}\right)$ & $\mathrm{X}_{2}$ & 20 & 28 & 36 \\
Days $(\mathrm{d})$ & $\mathrm{X}_{3}$ & 15 & 25 & 35 \\
\hline
\end{tabular}

The relationship between variables and response was described according to the following equation:

$$
Y=\alpha_{0}+\Sigma \alpha_{i} X_{i}+\Sigma \alpha_{i i} X_{i}^{2}+\Sigma \alpha_{i j} X_{i} X_{j}
$$

where $\mathrm{Y}$ is predicted response value, $\alpha_{0}$ is the intercept term, $\alpha_{\mathrm{i}}$ is liner team, $\alpha_{\mathrm{ii}}$ is squared term, $\alpha_{\mathrm{ij}}$ is interaction term, and $X_{i}$ and $X_{j}$ are the coded levels of independent variables.

Statistical analysis of the polynomial equation was utilized to assess analysis of variance (ANOVA). The quality of fit of the polynomial model was transmitted by the coefficient of determination $R^{2}$, and its statistical significance was measured by the F-test in the same program [41].

\subsection{Analytical Methods}

The fermentation broth was centrifuged at $4000 \times \mathrm{g} \mathrm{rpm}$ for $20 \mathrm{~min}$ to separate mycelia and supernatant. The mycelia and supernatant were evaporated to dryness and weighed. Dry samples were extracted with 50\% methanol for $30 \mathrm{~min}$ in an ultrasonic bath with $250 \mathrm{~W}, 40 \mathrm{KHz}$. The supernatant after extracting was filtered and detected ECH yield using L-2000 Elite high performance liquid chromatograph (HPLC). The analytical conditions: chromatographic column: ZORBAX Eclipse XDB $\mathrm{C}_{18}$ column $(250 \mathrm{~mm} \times 4.6 \mathrm{~mm}, 5 \mu \mathrm{m})$; mobile phase: acetonitrile $(\mathrm{A})-0.1 \%$ formic acid solution (B); elution condition: 0-10 $\mathrm{min}, 7-12 \% \mathrm{~A}$; 10-35 min, 12-75\% A; 35-50 min, 100\% A; column temperature: $25{ }^{\circ} \mathrm{C}$; detect wave length: $280 \mathrm{~nm}$; and flow: $1 \mathrm{~mL} / \mathrm{min}$.

\section{Conclusions}

In this study, endophyte Penicillium sp. $\mathrm{H} 1$ was isolated from the leaves of L. lucidum Ait. The yield of ECH was highly improved with endophytic fermentation under the optimal conditions, which were inoculation rate, temperature and days of $13.98 \%, 27.85{ }^{\circ} \mathrm{C}$ and 26.06 days, respectively, found using RSM. Due to the extensive pharmacological activities of ECH, the applications are increasing. We provided an alternative method for $\mathrm{ECH}$ production by endophytic fermentation in this paper. The yield of ECH was 150.47 times higher under the optimal conditions than under the control conditions. We speculated that ingredients of the medium were converted into ECH by endophytic fermentation. However, the specific mechanism of the biotransformation progress is unknown. In addition, profound studies are required to optimize the culture medium by adding other components such as carbon source, nitrogen source, precursors, ion and so on. Hence, further research is required.

Author Contributions: Conceptualization, F.X. and H.C.; methodology, F.X.; formal analysis, X.C. and H.G.; writing-original draft preparation, F.X.; writing—review and editing, H.C. and X.C.; and supervision, C.H.

Funding: This research was funded by Project of Shandong Province Key Research and Development Program (2017YYSP030).

Conflicts of Interest: The authors declare no conflict of interest. 


\section{References}

1. Bacon, C.W.; White, J.F., Jr. Microbial Endophytes; Marcel Dekker Inc.: New York, NY, USA, 2000.

2. Schulz, B.; Boyle, C.; Sieber, T. Microbial Root Endophytes; Springer: Berlin, Germany, 2006.

3. Card, S.; Johnson, L.; Teasdale, S.; Caradus, J. Deciphering endophyte behaviour: The link between endophyte biology and efficacious biological control agents. FEMS Microbiol. Ecol. 2016, 92, 8. [CrossRef] [PubMed]

4. Frank, A.C.; Saldierna-Guzmán, J.P.; Shay, J.E. Transmission of Bacterial Endophytes. Microorganisms 2017, 5, 4. [CrossRef] [PubMed]

5. Wani, Z.A.; Ashraf, N.; Mohiuddin, T.; Riyaz-Ul-Hassan, S. Plant-endophyte symbiosis, an ecological perspective. Appl. Microbiol. Biotechnol. 2015, 99, 2955-2965. [CrossRef] [PubMed]

6. Liotti, R.G.; da Silva Figueiredo, M.I.; da Silva, G.F.; de Mendonça, E.A.F.; Soares, M.A. Diversity of cultivable bacterial endophytes in Paullinia cupana and their potential for plant growth promotion and phytopathogen control. Microbiol. Res. 2018, 207, 8-18. [CrossRef] [PubMed]

7. Strobel, G.A. Endophytes as sources of bioactive products. Microbes Infect. 2003, 5, 535-544. [CrossRef]

8. Aly, A.H.; Debbab, A.; Proksch, P. Fungal endophytes: Unique plant inhabitants with great promises. Appl. Microbiol. Biotechnol. 2011, 90, 1829-1845. [CrossRef] [PubMed]

9. Busby, P.E.; Soman, C.; Wagner, M.R.; Friesen, M.L.; Kremer, J.; Bennett, A.; Morsy, M.; Eisen, J.A.; Leach, J.E.; Dangl, J.L. Research priorities for harnessing plant microbiomes in sustainable agriculture. PLoS Biol. 2017, 15, e2001793. [CrossRef] [PubMed]

10. Xu, F.; Wang, S.; Li, Y.; Zheng, M.; Xi, X.; Cao, H.; Cui, X.; Guo, H.; Han, C. Yield enhancement strategies of rare pharmaceutical metabolites from endophytes. Biotechnol. Lett. 2018, 40, 797-807. [CrossRef] [PubMed]

11. Kuang, R.; Sun, Y.; Zheng, X. Suppression of nitric oxide implicated in the protective effect of echinacoside on $\mathrm{H}_{2} \mathrm{O}_{2}$-induced PC12 cell injury. Nat. Prod. Commun. 2010, 5, 571-574. [PubMed]

12. Xiong, W.T.; Gu, L.; Wang, C.; Sun, H.X.; Liu, X. Anti-hyperglycemic and hypolipidemic effects of Cistanche tubulosa in type 2 diabetic db/db mice. J. Ethnopharmacol. 2013, 150, 935-945. [CrossRef] [PubMed]

13. Speroni, E.; Govoni, P.; Guizzardi, S.; Renzulli, C.; Guerra, M.C. Anti-inflammatory and cicatrizing activity of Echinacea pallida Nutt. root extract. J. Ethnopharmacol. 2002, 79, 265-272. [CrossRef]

14. Macková, A.; Mucaji, P.; Widowitz, U.; Bauer, R. In vitro anti-inflammatory activity of Ligustrum vulgare extracts and their analytical characterization. Nat. Prod. Commun. 2013, 8, 1509-1512. [PubMed]

15. Li, F.; Yang, X.; Yang, Y.; Guo, C.; Zhang, C.; Yang, Z.; Li, P. Antiosteoporotic activity of echinacoside in ovariectomized rats. Phytomedicine 2013, 20, 549-557. [CrossRef] [PubMed]

16. Li, F.; Yang, Y.; Zhu, P.; Chen, W.; Qi, D.; Shi, X.; Zhang, C.; Yang, Z.; Li, P. Echinacoside promotes bone regeneration by increasing OPG/RANKL ratio in MC3T3-E1 cells. Fitoterapia 2012, 83, 1443-1450. [CrossRef] [PubMed]

17. Yang, X.; Li, F.; Yang, Y.; Shen, J.; Zou, R.; Zhu, P.; Zhang, C.; Yang, Z.; Li, P. Efficacy and safety of echinacoside in a rat osteopenia model. Evid.-Based Complement. Altern. Med. 2013. [CrossRef] [PubMed]

18. Zhang, D.; Lu, C.; Yu, Z.; Wang, X.; Yan, L.; Zhang, J.; Li, H.; Wang, J.; Wen, A. Echinacoside Alleviates UVB Irradiation-Mediated Skin Damage via Inhibition of Oxidative Stress, DNA Damage, and Apoptosis. Oxid. Med. Cell Longev. 2017, 2017, 6851464. [CrossRef] [PubMed]

19. Facino, R.M.; Carini, M.; Aldini, G.; Saibene, L.; Pietta, P.; Mauri, P. Echinacoside and caffeoyl conjugates protect collagen from free radical-induced degradation: A potential use of Echinacea extracts in the prevention of skin photodamage. Planta Med. 1995, 61, 510-514. [CrossRef] [PubMed]

20. Li, X.; Gou, C.; Yang, H.; Qiu, J.; Gu, T.; Wen, T. Echinacoside ameliorates D-galactosamine plus lipopolysaccharide-induced acute liver injury in mice via inhibition of apoptosis and inflammation. Scand. J. Gastroenterol. 2014, 49, 993-1000. [CrossRef] [PubMed]

21. Dai, L.H.; Shen, Y.M.; Wu, Y.H.; Yu, X.P.; Hu, H.J.; Mi, Y.J.; Chen, J.J. [Effect of echinacoside on replication and antigen expression of hepatitis B virus]. Zhongguo Zhong Yao Za Zhi 2015, 40, 3047-3052. [PubMed]

22. Wu, Y.; Li, L.; Wen, T.; Li, Y.Q. Protective effects of echinacoside on carbon tetrachloride-induced hepatotoxicity in rats. Toxicology 2007, 232, 50-56. [CrossRef] [PubMed]

23. Shiao, Y.J.; Su, M.H.; Lin, H.C.; Wu, C.R. Echinacoside ameliorates the memory impairment and cholinergic deficit induced by amyloid beta peptides via the inhibition of amyloid deposition and toxicology. Food Funct. 2017, 8, 2283-2294. [CrossRef] [PubMed] 
24. Zhang, D.; Li, H.; Wang, J.B. Echinacoside inhibits amyloid fibrillization of HEWL and protects against A $\beta$-induced neurotoxicity. Int. J. Biol. Macromol. 2015, 72, 243-253. [CrossRef] [PubMed]

25. Wang, Y.H.; Xuan, Z.H.; Tian, S.; Du, G.H. Echinacoside Protects against 6-Hydroxydopamine-Induced Mitochondrial Dysfunction and Inflammatory Responses in PC12 Cells via Reducing ROS Production. Evid.-Based Complement. Altern. Med. 2015, 2015, 189239. [CrossRef] [PubMed]

26. Chen, W.; Lin, H.R.; Wei, C.M.; Luo, X.H.; Sun, M.L.; Yang, Z.Z.; Chen, X.Y.; Wang, H.B. Echinacoside, a phenylethanoid glycoside from Cistanche deserticola, extends lifespan of Caenorhabditis elegans and protects from A $\beta$-induced toxicity. Biogerontology 2017, 19, 47-65. [CrossRef] [PubMed]

27. Zhang, J.; Zhang, Z.; Xiang, J.; Cai, M.; Yu, Z.; Li, X.; Wu, T.; Cai, D. Neuroprotective Effects of Echinacoside on Regulating the Stress-Active p38MAPK and NF-кB p52 Signals in the Mice Model of Parkinson's Disease. Neurochem. Res. 2017, 42, 975-985. [CrossRef] [PubMed]

28. Jiang, Z.; Wang, J.; Li, X.; Zhang, X. Echinacoside and Cistanche tubulosa (Schenk) R. wight ameliorate bisphenol A-induced testicular and sperm damage in rats through gonad axis regulated steroidogenic enzymes. J. Ethnopharmacol. 2016, 193, 321-328. [CrossRef] [PubMed]

29. Jiang, Z.; Zhou, B.; Li, X.; Kirby, G.M.; Zhang, X. Echinacoside Increases Sperm Quantity in Rats by Targeting the Hypothalamic. Androgen Receptor. Sci. Rep. 2018, 8, 3839. [CrossRef] [PubMed]

30. Dong, L.; Wang, H.; Niu, J.; Zou, M.; Wu, N.; Yu, D.; Wang, Y.; Zou, Z. Echinacoside induces apoptotic cancer cell death by inhibiting the nucleotide pool sanitizing enzyme MTH1. Onco Targets Ther. 2015, 8, 3649-3664. [PubMed]

31. Dong, L.; Yu, D.; Wu, N.; Wang, H.; Niu, J.; Wang, Y.; Zou, Z. Echinacoside Induces Apoptosis in Human SW480 Colorectal Cancer Cells by Induction of Oxidative DNA Damages. Int. J. Mol. Sci. 2015, 16, 14655-14668. [CrossRef] [PubMed]

32. Wang, W.; Luo, J.; Liang, Y.; Li, X. Echinacoside suppresses pancreatic adenocarcinoma cell growth by inducing apoptosis via the mitogen-activated protein kinase pathway. Mol. Med. Rep. 2016, 13, 2613-2618. [CrossRef] [PubMed]

33. Kuo, C.H.; Hsiao, F.W.; Chen, J.H.; Hsieh, C.W.; Liu, Y.C.; Shieh, C.J. Kinetic aspects of ultrasound-accelerated lipase catalyzed acetylation and optimal synthesis of 4'-acetoxyresveratrol. Ultrason. Sonochem. 2013, 20, 546-552. [CrossRef] [PubMed]

34. Gu, F.; Xu, F.; Tan, L.; Wu, H.; Chu, Z.; Wang, Q. Optimization of enzymatic process for vanillin extraction using response surface methodology. Molecules 2012, 17, 8753-8761. [CrossRef] [PubMed]

35. Wu, K.; Ding, L.; Zhu, P.; Li, S.; He, S. Application of the Response Surface Methodology to Optimize the Fermentation Parameters for Enhanced Docosahexaenoic Acid (DHA) Production by sp ATCC 26185. Molecules 2018, 23, 974. [CrossRef] [PubMed]

36. Wang, Y.; Zhang, M.; Zhang, Z.; Jiang, Z.; Jiang, J.; Gao, X.; Yue, P. Multiple responses optimization of instant dark tea production by submerged fermentation using response surface methodology. J. Food Sci. Technol. 2018, 55, 2579-2586. [CrossRef] [PubMed]

37. Peiran, L.; Ying, L.; Mingzhuo, Z.; Ye, Y.; Xiuming, C. The development of a Panax notoginseng medicinal liquor processing technology using the response surface method and a study of its antioxidant activity and its effects on mouse melanoma B16 cells. Food Funct. 2017, 8, 4251-4264. [CrossRef] [PubMed]

38. Wang, W.; Di, Z.; Li, R.; Tian, J. Statistical Optimization of the Content Composition Precursors Using Response Surface Methodology to Enhance Agaricoglyceride A Production from the Shaggy Ink Cap Medicinal Mushroom, Coprinus comatus (Higher Basidiomycetes) Mycelia. Int. J. Med. Mushrooms 2015, 17, 977-985. [CrossRef] [PubMed]

39. Bodhankar, S.; Grover, M.; Hemanth, S.; Reddy, G.; Rasul, S.; Yadav, S.K.; Desai, S.; Mallappa, M.; Mandapaka, M.; Srinivasarao, C. Maize seed endophytic bacteria: Dominance of antagonistic, lytic enzyme-producing Bacillus spp. 3 Biotech 2017, 7, 232. [CrossRef] [PubMed]

40. Zhang, Q.; Li, Y.; Xu, F.; Zheng, M.; Xi, X.; Zhang, X.; Han, C. Optimization of Submerged Fermentation Medium for Matrine Production by, an Endophytic Fungus Harboring Seeds of, Using Response Surface Methodology. Mycobiology 2017, 45, 90-96. [CrossRef] [PubMed] 
41. Zhang, Y.J.; Li, Q.; Zhang, Y.X.; Wang, D.; Xing, J.M. Optimization of succinic acid fermentation with Actinobacillus succinogenes by response surface methodology (RSM). J. Zhejiang Univ. Sci. B 2012, 13, 103-110. [CrossRef] [PubMed]

Sample Availability: Samples of the compounds are available from the authors.

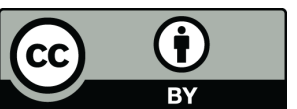

(C) 2018 by the authors. Licensee MDPI, Basel, Switzerland. This article is an open access article distributed under the terms and conditions of the Creative Commons Attribution (CC BY) license (http://creativecommons.org/licenses/by/4.0/). 